\title{
Effect of Hydrofluoric Acid Etching Duration on the Roughness and Flexural Strength of a Lithium Disilicate-Based Glass Ceramic
}

\author{
Lucas Villaça ZOGHEIB ${ }^{1}$ \\ Alvaro DELLA BONA ${ }^{1}$ \\ Estevão Tomomitsu KIMPARA2 \\ John F. MCCABE ${ }^{3}$ \\ ${ }^{1}$ Department of Restorative Dentistry, Dental School, University of Passo Fundo, Passo Fundo, RS, Brazil \\ ${ }^{2}$ Department of Dental Materials and Prosthodontics, São José dos Campos Dental School, \\ UNESP - Univ. Estadual Paulista, São José dos Campos, SP, Brazil \\ ${ }^{3}$ Dental Materials Unit, Newcastle University, Newcastle upon Tyne, United Kingdom
}

\begin{abstract}
The aim of this study was to examine the effect of different acid etching times on the surface roughness and flexural strength of a lithium disilicate-based glass ceramic. Ceramic bar-shaped specimens (16 $\mathrm{mm}$ x $2 \mathrm{~mm}$ x $2 \mathrm{~mm}$ ) were produced from ceramic blocks. All specimens were polished and sonically cleaned in distilled water. Specimens were randomly divided into 5 groups ( $\mathrm{n}=15$ ). Group A (control) no treatment. Groups B-E were etched with 4.9\% hydrofluoric acid (HF) for 4 different etching periods: $20 \mathrm{~s}, 60 \mathrm{~s}, 90 \mathrm{~s}$ and $180 \mathrm{~s}$, respectively. Etched surfaces were observed under scanning electron microscopy. Surface profilometry was used to examine the roughness of the etched ceramic surfaces, and the specimens were loaded to failure using a 3-point bending test to determine the flexural strength. Data were analyzed using one-way ANOVA and Tukey's test $(\alpha=0.05)$. All etching periods produced significantly rougher surfaces than the control group $(\mathrm{p}<0.05)$. Roughness values increased with the increase of the etching time. The mean flexural strength values were $(\mathrm{MPa})$ : $\mathrm{A}=417 \pm 55 ; \mathrm{B}=367 \pm 68 ; \mathrm{C}=363 \pm 84 ; \mathrm{D}=329 \pm 70 ;$ and $\mathrm{E}=314 \pm 62$. HF etching significantly reduced the mean flexural strength as the etching time increased $(\mathrm{p}=0.003)$. In conclusion, the findings of this study showed that the increase of HF etching time affected the surface roughness and the flexural strength of a lithium disilicate-based glass ceramic, confirming the study hypothesis.
\end{abstract}

Key Words: hydrofluoric acid, CAD/CAM, lithium disilicate glass ceramic, roughness, flexural strength.

\section{INTRODUCTION}

Dental ceramic restorations are extensively used, because they are durable, esthetically appealing, and provide excellent biocompatibility (1). This preference is directly related to the success of ceramic resin bond that contributes to the restoration longevity.

The retention of the lithium silicate ceramic veneer can be satisfactorily achieved by two factors: ceramic surface treatment from acid etching, and silane coupling agent application prior to cementation with a resin cement (1-4). In general, the structure of veneering ceramic has been described as an amorphous and glass matrix that consists of a random network of cross-linked silica in a tetrahedral arrangement, which is embedded in varying amounts of undissolved feldspar and reinforcement crystals like lithium disilicate $(1,4)$.

For ceramic surface treatment, the acid reacts with the glass matrix that contains silica and forms hexafluorosilicates. This glass matrix is selectively removed and the crystalline structure is exposed. As a result, the surface of the ceramic becomes rough, which is expected for micromechanical retention on the ceramic surface $(5,6)$. This roughly etched surface also helps to provide more surface energy prior to combining with the silane solution (7).

In vitro studies have reported positive effects of hydrofluoric acid (HF) etching on the strength of glasses by removing or stabilizing surface defects and on surface topography increasing roughness for adhesive bonding 
$(2,8,9)$. On the other hand, HF etching can weaken the flexural strength of ceramics (10).

The addition of lithium disilicate crystals in glass ceramics aimed to improve strength and durability over conventional dental ceramics (12). In addition, the development of new technologies, such as computeraided design/computer aided manufacturing $(\mathrm{CAD} /$ CAM), allowed for an easier and more practical fabrication of lithium silicate-based all-ceramic restorations (11).

Although some studies have reported on the effect of different HF etching times on bond strength $(6,7)$, roughness (2) and flexural strength $(1,2)$, none of these studies addressed such effects on lithium disilicate-based glass ceramics. Therefore, the purpose of this study was to examine the effect of different HF etching times on the roughness and flexure strength of a lithium disilicatebased glass ceramic, testing the hypothesis that different HF etching times produces different roughness patterns and flexural strength values for this ceramic.

\section{MATERIAL AND METHODS}

Seventy-five bar-shaped ceramic specimens (16 $\mathrm{mm} \times 2 \mathrm{~mm} \times 2 \mathrm{~mm}$ ) were fabricated from partially crystallized lithium disilicate-based glass blocks (IPS e.max CAD; Ivoclar Vivadent, Schaan, Liechtenstein). The ceramic blocks were cut in rectangular slices $(16 \mathrm{~mm}$ x $2 \mathrm{~mm}$ ) using a low speed diamond wheel saw (Model 650; South Bay Tech Inc, San Clemente, CA, USA). The ceramic slices were wet polished up to 1000 -grit silicon carbide paper and polishing liquid on a grinding device (Metaserv; Metallurgical Services, Betchworth, Survey, England) to remove external irregular scratches and defects. The ceramic slices were further cut in bar-shaped specimens using the same low speed diamond wheel saw. All ceramic specimens were sonically cleaned in distilled water for $15 \mathrm{~min}$. Specimens were crystallized following the firing program and vacuum pump furnace recommended by the manufacturer.

The ceramic specimens were randomly divided into 5 groups ( $\mathrm{n}=15)$ according to the following ceramic surface treatment:

Group A (control) - no ceramic surface treatment; Group B - HF etched (4.9\% hydrofluoric acid gel; Ivoclar-Vivadent) for $20 \mathrm{~s}$; Group C - HF etched for 60 s; Group D - HF etched for 90 s; Group E - HF etched for $180 \mathrm{~s}$.

As HF offers hazardous effects to health, the ceramic specimens were etched in a laboratory cupboard under ventilation, wearing acid resistant gloves, coat cover with plastic apron and face shield. The etching gel was rinsed in a polyethylene cup for $30 \mathrm{~s}$ and the diluted solution was neutralized using the neutralizing powder (calcium carbonate, $\mathrm{CaCO}_{3}$ and sodium carbonate, $\mathrm{Na}_{2} \mathrm{CO}_{3}$ ) for $5 \mathrm{~min}$. The treated specimens were sonically cleaned in distilled water for $5 \mathrm{~min}$.

Randomly selected specimens from each group were prepared for morphological examination under a scanning electron microscope (FEI/Philips XL30 ESEM; Philips Electronic Instruments Co, Mahwah, NJ, USA).

In all groups, surface roughness was determined using a profilometer (Mitutoyo Surftest SV-2000; Mitutoyo, Andover, Hampshire, UK), and the $R a$ parameter values were recorded. $R a$ is the average roughness value of a surface. The lower the $R a$ value the smoother the surface. The profilometer parameters were set as follows: cutoff length of $0.8 \mathrm{~mm}$, transverse length of $4.0 \mathrm{~mm}$, and a measuring range of $0-12.5 \mathrm{~mm}$. Each specimen was scanned 4 times in different areas of the specimen and average the $R a$ value.

The flexural strength was determined with a 3-point bending test in a universal testing machine (Model 5567; Instron Ltd, Buckinghamshire, England). The specimens were placed flat on a mountain jig with rounded supporting rods $12 \mathrm{~mm}$ apart, and the center of the specimens was loaded (load cell $1 \mathrm{KN}$ ) with a rounded chisel (radius $3 \mathrm{~mm}$ ) at a crosshead speed of $0.5 \mathrm{~mm} /$ min until fracture occurred. The following equation was used for flexural strength $(\sigma)$ calculation: $\sigma=3 \mathrm{Pl} / 2 \mathrm{wb}^{2}$, where $\mathrm{P}$ is the fracture load (in N); 1 is the test span (12 $\mathrm{mm}$ ); $\mathrm{w}$ is the width of the specimen (in $\mathrm{mm}$ ); and $\mathrm{b}$ is the thickness of the specimen (in $\mathrm{mm}$ ).

One-way ANOVA and Tukey's HSD test $(\alpha=0.05)$ were used to assess the statistically significant differences of ceramic surface roughness and flexural strength values among the different HF etching times.

\section{RESULTS}

The mean and standard deviation values for Ra and flexural strength of all experimental groups are presented in Table 1.

Significant differences in mean $R a$ values were found among the groups. Group A $(0.06 \pm 0.01)$ showed the lowest mean $R a$ value, while Group E $(0.16 \pm 0.1)$ showed the highest mean $R a$ value $(\mathrm{p}<0.05)$. There were no significant differences $(p>0.05)$ between the 
mean Ra values of groups B and C, groups $\mathrm{C}$ and $\mathrm{D}$, and groups $\mathrm{D}$ and $\mathrm{E}$.

Significant differences in mean flexural strength values were also found (Table 1). The control group showed significantly higher $(\mathrm{p}>0.05)$ mean values than groups $\mathrm{D}$ and $\mathrm{E}$. There were no significant differences ( $p>0.05$ ) among groups $\mathrm{A}, \mathrm{B}$ and $\mathrm{C}$, and among groups $\mathrm{B}$, $\mathrm{C}, \mathrm{D}$ and $\mathrm{E}$. However, the mean flexural strength values decreased with the increase HF etching time increasing. There was a positive correlation between $R a$ and flexural strength values $\left(r^{2}=96 \%\right)$ (Fig. 1$)$.

Analysis of the different ceramic surface treatments by scanning electron microscopy (SEM) provided valuable information concerning the resulting topography. The untreated ceramic surface is smooth and homogeneous (Fig. 2A), becoming increasingly porous and irregular because of the dissolution of the glass phase after HF etching (Figs. 2B-E). As a consequence, voids and channels appeared larger and deeper, as the etching period increases. HF etching patterns appeared more pronounced and aggressive in groups $\mathrm{D}$ and $\mathrm{E}$, where lithium disilicate crystals can be easily seen protruded from the glassy matrix.

\section{DISCUSSION}

Standard adhesive protocol for ceramic restorations requires etching and silanating the fitting surface of the porcelain (13). Acid etching of porcelain has been widely used to enhance the retention between bonding resins and ceramic restorations. Some studies have suggested that etching is needed preferably with HF than with phosphoric acid $(4,13)$. Notwithstanding, phosphoric acid does not etch ceramics but it may

Table 1. Mean values and standard deviations for surface roughness and flexural strength in all experimental groups.

\begin{tabular}{lcc}
\hline $\begin{array}{l}\text { Surface treatment } \\
\text { (HF etching time) }\end{array}$ & $\begin{array}{c}\text { Surface roughness } \\
(R a ; \mu \mathrm{m})\end{array}$ & $\begin{array}{c}\text { Flexural strength } \\
(\mathrm{MPa})\end{array}$ \\
\hline Untreated (A) & $0.06 \pm 0.01 \mathrm{a}$ & $417 \pm 55 \mathrm{a}$ \\
$20 \mathrm{~s}(\mathrm{~B})$ & $0.09 \pm 0.05 \mathrm{~b}$ & $367 \pm 68 \mathrm{ab}$ \\
$60 \mathrm{~s}(\mathrm{C})$ & $0.12 \pm 0.05 \mathrm{bc}$ & $363 \pm 84 \mathrm{ab}$ \\
$90 \mathrm{~s}(\mathrm{D})$ & $0.14 \pm 0.06 \mathrm{~cd}$ & $329 \pm 70 \mathrm{~b}$ \\
$180 \mathrm{~s}(\mathrm{E})$ & $0.16 \pm 0.10 \mathrm{~d}$ & $314 \pm 62 \mathrm{~b}$ \\
\hline
\end{tabular}

Different letters indicate statistically significant difference (Tukey's test; $\mathrm{p}<0.05$ ). improve the surface energy by cleaning the ceramic surface (14).

Ceramic etching is a dynamic process and the impact is dependent on substrate constitution, surface topography, acid concentration and etching time $(2,15)$.

Regarding the etching time, many studies have been done with different kinds of ceramics and HF etchants $(3,5,6,15)$. Chen et al. (5) evaluated two HF etchants (2.5 and 5\%) and seven different etching times $(0,30,60,90,120,150$, and $180 \mathrm{~s})$. Etching periods above $30 \mathrm{~s}$ effectively enhanced the bond strength to resin. Of the two etching agents applied to the unsilanated porcelain, the buffered $2.5 \% \mathrm{HF}$ produced higher bond strengths to resin than the $5 \% \mathrm{HF}$ for all etching time periods, except for $180 \mathrm{~s}$. Guler et al. (3) evaluated the effect of different $9.6 \% \mathrm{HF}$ etching times $(30 \mathrm{~s}, 30+30$ $\mathrm{s}, 60 \mathrm{~s}, 60+60 \mathrm{~s}, 120 \mathrm{~s}$, and $180 \mathrm{~s}$ ) on porcelain and 2 adhesive systems on shear bond strengths to resin composite. The authors concluded that HF etching for $120 \mathrm{~s}$ provided adequate bond strength of porcelain to resin.

It is known that HF etching of porcelain provides the necessary surface roughness to mechanical interlocking but overetching could have a weakening effect on the porcelain (15-17). Therefore, it is important to know the adequate HF etching time for micromechanical retention without weakening the ceramic. this is the reason why the present study investigated the adequate etching protocol for a lithium disilicate-based glass ceramic.

Since HF etching was first suggested as a ceramic surface treatment for resin bonding, many different combinations between etching periods and

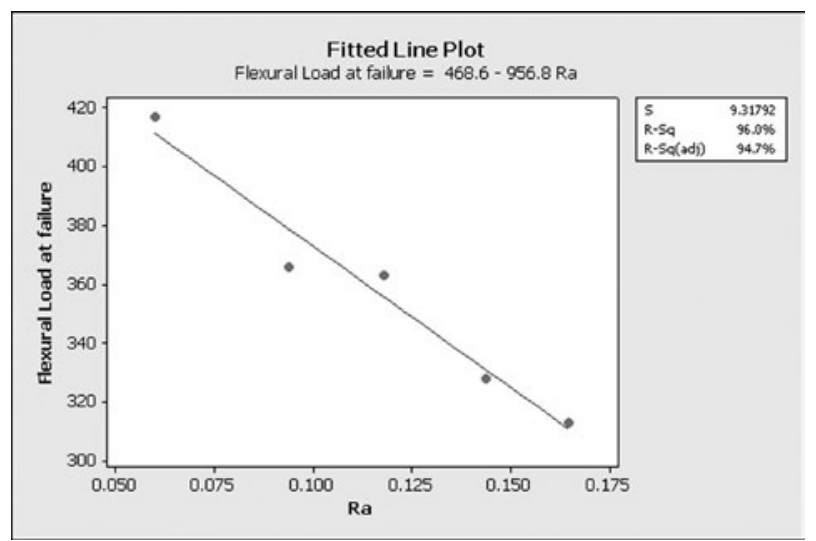

Figure 1. Fitted line plot of flexural load at failure and surface roughness $(R a ; \mu \mathrm{m})$. 
acid concentration have been suggested and used (1$6,8,14,18-20$ ). Wolf et al. (8), evaluated the surface roughness of a feldspathic porcelain etched with $9.5 \% \mathrm{HF}$ for $30,60,150$, and $300 \mathrm{~s}$ and the tensile bond strength to resin. The authors found a positive correlation between ceramic surface roughness and increasing HF etching
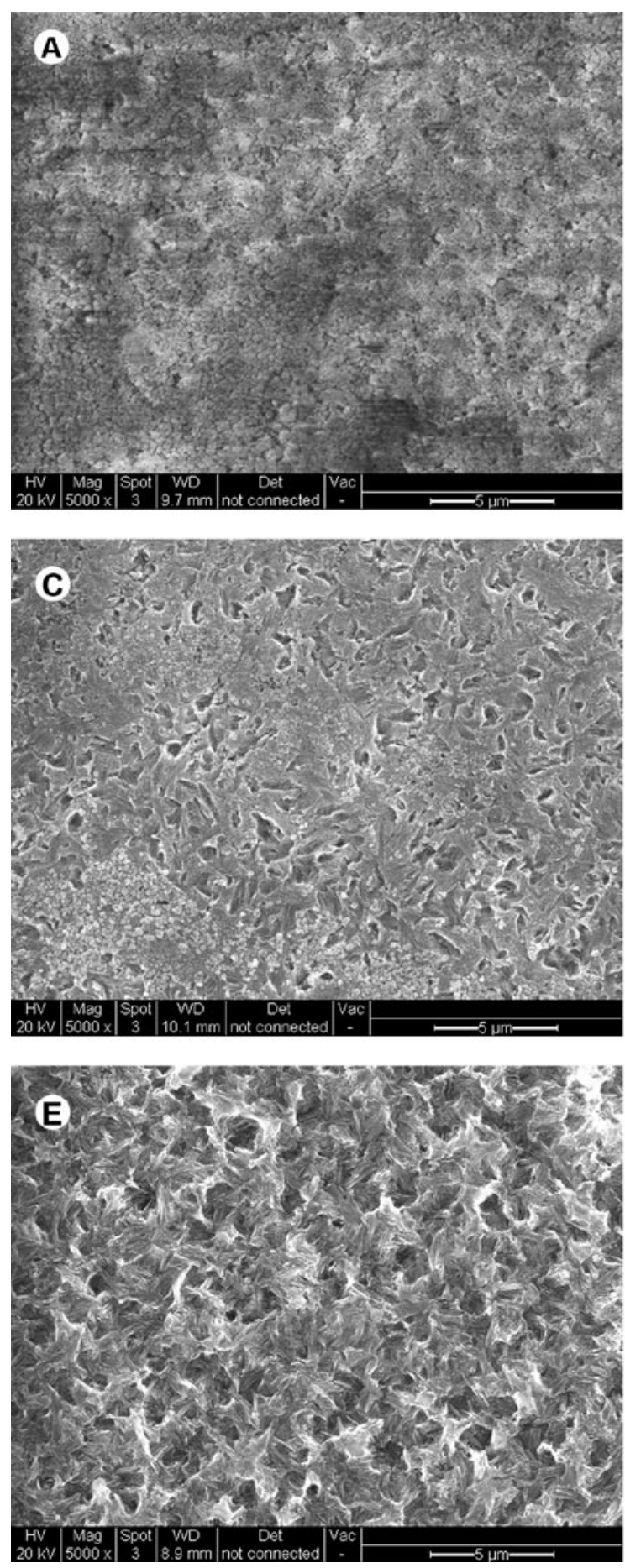

time, which agreed with other studies $(2,19)$ and with the present study.

In the present study, $\mathrm{HF}$ etching increased ceramic roughness in all experimental groups, even for periods as short as $20 \mathrm{~s}$, which is the etching time recommended by the manufacturer. Significantly higher mean $R a$ values
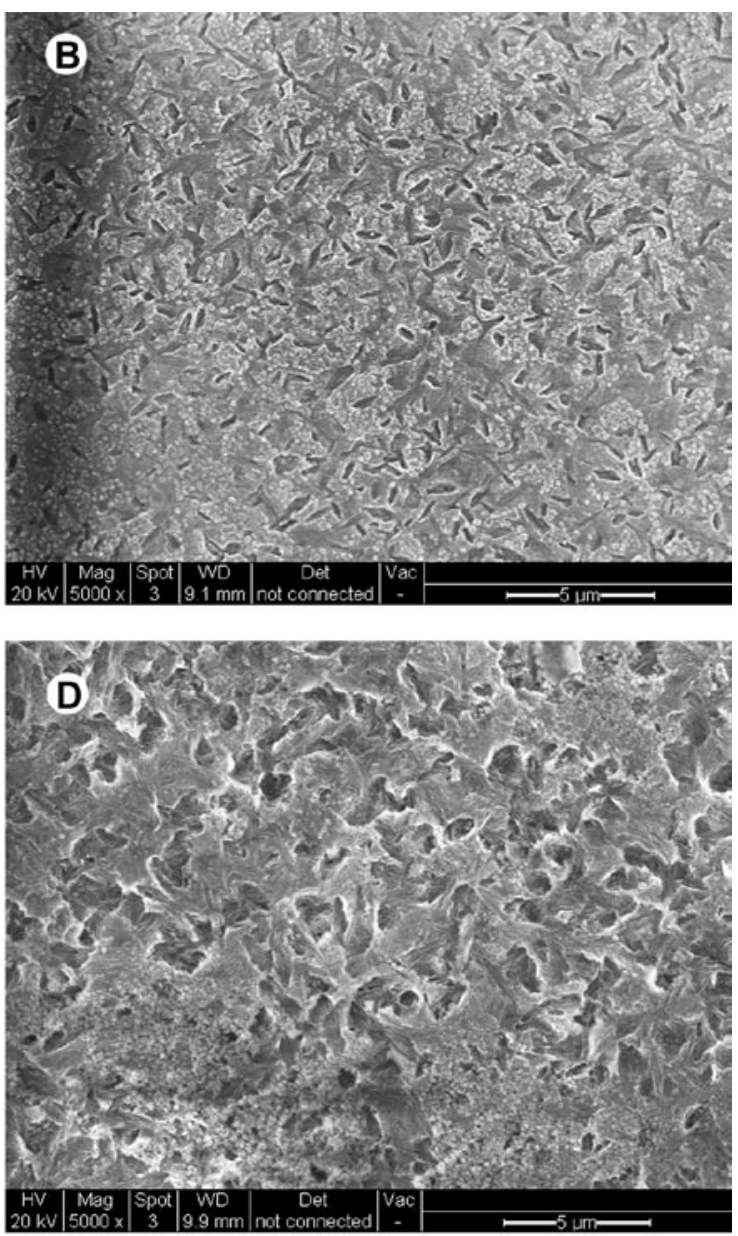

Figure 2. Panel of representative SEM micrographs of the surface of HF-etched lithium disilicate-based glass ceramic after application of the different etching times evaluated in the study. Original magnification $\times 5,000$.
$A=$ not etched
$\mathrm{B}=20-\mathrm{s}$ etching
$\mathrm{C}=60$-s etching
$\mathrm{D}=90$-s etching
$\mathrm{E}=180-\mathrm{s}$ etching 
were found for groups $\mathrm{D}$ and $\mathrm{E}$. The mean $R a$ values for the etching times of $0,20,60,90$ and $180 \mathrm{~s}$ were 0.06 , $0.09,0.12,0.14$, and $0.16 \mu \mathrm{m}$ respectively. Chen et al. (6), using $2.5 \% \mathrm{HF}$, observed that etching periods for more than $30 \mathrm{~s}$ effectively enhanced the bond strength between a feldspathic porcelain and a resin cement. Different results were found and explained by Della Bona et al. $(15,18)$. The authors suggested that etching mechanisms change according to the type of etchant and ethcing time, and the ceramic microstructure and composition (18). Therefore, it is difficult to compare the present results to those of previous studies that used different ceramics and etching protocols. However, associating the mean $R a$ values with the SEM images it is possible to suggest that the ceramic used in the present study need more than a 60 -s HF etching time to produce adequate retentive surface for resin bonding. The SEM micrographs clearly revealed the effect of the different etching periods on the microstructure of the ceramic (Figs. 2A-E). For cementation of e-max CAD restorations, the manufacturer recommends an etching time of $20 \mathrm{~s}$ using a $4.9 \% \mathrm{HF}$ gel. The ceramic surface roughness produced by this etching time is significantly lower than etching for either 90 or $180 \mathrm{~s}$ (Table 1 and Figs. 2 B-E). In addition, Figures $2 \mathrm{~B}$ and $2 \mathrm{C}$ (ceramic etched for 20 and $60 \mathrm{~s}$, respectively) show minor surface disruptions compared to Figures 2D and 2E (ceramic etched for 90 and $180 \mathrm{~s}$, respectively). This suggests different abilities for micromechanical retention and bond strength to resin. Further studies on the bond strength are necessary to confirm this hypothesis.

In the current investigation the flexural strength of the lithium disilicate-based glass ceramic decreased after HF etching. The reason of this could be explained because the amount of the glass phase involving the lithium disilicate crystals. SEM images clearly revealed less amount of glassy matrix in the control group compared with all experimental groups. Similar results testing different ceramics have been described, confirming the weakening effect of HF etching $(1,8,12)$.

It should be noted that this study has some limitations. First, the 3-point bending test used does not reflect the actual fracture strengths in the clinical situation because of the different environmental and loading conditions. Second, once ceramics restorations are resin bonded, the strength of the tooth-resin-ceramic system improves. Third, only one HF concentration was evaluated. Further bond strength studies investigating the resin-ceramic interface after use of different etching times and acid concentrations are necessary. Future studies should consider clinical conditions like wet environment and cyclic load of bonded ceramic restorations.

The findings of this study showed that the increase of HF etching time affected the surface roughness and the flexural strength of a lithium disilicate-based glass ceramic, confirming the study hypothesis.

\section{RESUMO}

O objetivo deste estudo foi avaliar o efeito de diferentes tempos de condicionamento ácido na rugosidade de superfície e resistência flexural de uma cerâmica à base de disilicato de lítio. Espécimes cerâmicos em forma de barra (16 $\mathrm{mm} \times 2 \mathrm{~mm} \times 2 \mathrm{~mm}$ ) foram produzidos a partir de blocos cerâmicos. Todos os espécimes foram polidos e limpos em banho de ultrasom em água destilada. Os espécimes foram aleatoriamente divididos em 5 grupos $(n=15)$. Grupo A (controle) sem tratamento. Grupos B-E condicionamento com ácido fluorídrico $4,9 \%$ (HF) por 4 diferentes períodos de condicionamento: 20 s, 60 s, 90 s e 180 s, respectivamente. As superfícies condicionadas foram observadas sob microscopia eletrônica de varredura. Perfilometria de superfície foi utilizada para examinar a rugosidade das superfícies condicionadas, e os espécimes foram carregados até a falha pelo teste de flexão três pontos. Os valores foram analisados usando ANOVA um fator e teste de Tukey $(\alpha=0,05)$. Todos os períodos de condicionamento produziram superfícies significantemente mais rugosas do que o grupo controle $(p<0,05)$. Os valores de rugosidade aumentaram com o tempo de condicionamento. Os valores médios de resistência à flexão foram $(\mathrm{MPa}): \mathrm{A}=417 \pm 55 ; \mathrm{B}=367 \pm 68$; $\mathrm{C}=363 \pm 84 ; \mathrm{D}=329 \pm 70 ; \mathrm{e} \mathrm{E}=314 \pm 62$. O condicionamento com HF reduziu significativamente os valores médios de resistência à flexão conforme o tempo de condicionamento aumentou $(\mathrm{p}=0,003)$. Os achados deste estudo mostraram que o aumento do tempo de condicionamento ácido influenciou a rugosidade de superfície e resistência flexural de uma cerâmica à base de disilicato de lítio confirmando a hipótese do mesmo.

\section{ACKNOWLEDGEMENTS}

The authors acknowledge Ivoclar-Vivadent for providing the necessary materials used in this study and CAPES (Brazilian Federal Agency for the Support and Evaluation of Graduate Education) for the financial support provided (grant\#3242/08-0). The authors also acknowledge ACMA unit at School of Chemistry and the School of Chemical Engineering and Advanced Materials, Newcastle University for the SEM analysis.

\section{REFERENCES}

1. Hooshmand T, Parvizi S, Keshvad A. Effect of surface acid etching on the biaxial flexural strength of two hot-pressed glass ceramics. J Prosthodont 2008; 17:415-419.

2. Addison O, Marquis PM, Fleming GJ. The impact of hydrofluoric acid surface treatments on the performance of a porcelain laminate restorative material. Dent Mater 2007;23:461-468. 
3. Guler AU, Yilmaz F, Yenisey M, Guler E, Ural C. Effect of acid etching time and a self-etching adhesive on the shear bond strength of composite resin to porcelain. J Adhes Dent 2006;8:21-25.

4. Klosa K, Wolfart S, Lehmann F, Wenz HJ, Kern M. The effect of storage conditions, contamination modes and cleaning procedures on the resin bond strength to lithium disilicate ceramic. J Adhes Dent 2009;11:127-135.

5. Chen JH, Matsumura H, Atsuta M. Effect of etchant, etching period, and silane priming on bond strength to porcelain of composite resin. Oper Dent 1998;23:250-257.

6. Chen JH, Matsumura H, Atsuta M. Effect of different etching periods on the bond strength of a composite resin to a machinable porcelain. J Dent 1998;26:53-58.

7. Jardel V, Degrange M, Picard B, Derrien G. Surface energy of etched ceramic. Int J Prosthodont 1999;12:415-418.

8. Wolf DM, Powers JM, O'Keefe KL. Bond strength of composite to etched and sandblasted porcelain. Am J Dent 1993;6:155-158.

9. Magne P, Kwon KR, Belser UC, Hodges JS, Douglas WH. Crack propensity of porcelain laminate veneers: a simulated operatory evaluation. J Prosthet Dent 1999;81:327-334.

10. Yen TW, Blackman RB, Baez RJ. Effect of acid etching on the flexural strength of a feldspathic porcelain and a castable glass ceramic. J Prosthet Dent 1993;70:224-233.

11. Wiedhahn K. From blue to white: new high-strength material for Cerec-IPS e.max CAD LT. Int J Comput Dent 2007;10:79-91.

12. Della Bona A. Bonding to ceramics: scientific evidences for clinical dentistry. São Paulo: Artes Médicas; 2009.
13. Stewart GP, Jain P, Hodges J. Shear bond strength of resin cements to both ceramic and dentin. J Prosthet Dent 2002;88:277-284.

14. Canay S, Hersek N, Ertan A. Effect of different acid treatments on a porcelain surface. J Oral Rehabil 2001;28:95-101.

15. Della Bona A, Anusavice KJ, Hood JA. Effect of ceramic surface treatment on tensile bond strength to a resin cement. Int $\mathrm{J}$ Prosthodont 2002;15:248-255.

16. Della Bona A, Van Noort R. Shear vs. tensile bond strength of resin composite bonded to ceramic. J Dent Res 1995;74:1591-1596.

17. Addison O, Fleming GJ. The influence of cement lute, thermocycling and surface preparation on the strength of a porcelain laminate veneering material. Dent Mater 2004;20:286292.

18. Della Bona A, Anusavice KJ. Microstructure, composition, and etching topography of dental ceramics. Int $\mathrm{J}$ Prosthodont 2002;15:159-167.

19. Chaiyabutr Y, McGowan S, Phillips KM, Kois JC, Giordano RA. The effect of hydrofluoric acid surface treatment and bond strength of a zirconia veneering ceramic. J Prosthet Dent 2008;100:194202.

20. Naves LZ, Soares CJ, Moraes RR, Gonçalves LS, Sinhoreti MA, Correr-Sobrinho L. Surface/interface morphology and bond strength to glass ceramic etched for different periods. Oper Dent 2010;35:420-427. 